\title{
PROJETO MULHERES EM STEM²D E A IMPLEMENTAÇÃO DE OFICINAS EXPERIMENTAIS: METODOLOGIAS ADAPTADAS DURANTE A PANDEMIA DA COVID-19
}

DOI: 10.37702/2175-957X.COBENGE.2021.3575

Sophia Rodrigues Laranja - sophialaranjaa@gmail.com Instituto Tecnológico de Aeronáutica Rua Alfredo Pujol 167

20561-230 - Rio de Janeiro - RJ

Thais Cardoso de Oliveira - thaiscardoso@me.com

ITA

Rua Noel Rosa 93

12062-220 - Taubaté - SP

Natália JOdas - najodas@gmail.com Instituto Tecnológico de Aeronáutica

Rua Clóvis Bevilaqua 617

12242-790 - São José dos Campos - SP

Sueli Sampaio Damin Custódio - smdamin@gmail.com ITA

Rua das Baleias 95

12246-290 - São José dos Campos - SP

Lara Kühl Teles - Ikteles@ita.br Instituto Tecnológico de Aeronáutica Rua Helena david Neme 94 12245-310 - São José dos Campos - SP

Maria Margareth Da Silva - meg@ita.br Instituto Tecnológico de Aeronáutica Rua João Fonseca Dos Santos 100 12230-088 - São José dos Campos - SP

Leila Ribeiro dos Santos - leila@ita.br Instituto Tecnológico de Aeronáutica Praça Marechal do Ar Eduardo Gomes 50 
12228-900 - São José dos Campos - SP

Fernanda de Andrade Pereira - fpereira@ita.br

Instituto Tecnológico de Aeronáutica

Praça Marechal Eduardo Gomes 50

12228-900 - São José dos Campos - SP

Izabela Batista Henriques - izabela@ita.br

Instituto Tecnológico de Aeronáutica

Rua Benedito Alvarenga Carvalho 91

12246-120 - São José dos Campos - SP

Monica Mitiko Soares Matsumoto - mmatsumo@gmail.com

Instituto Tecnológico de Aeronáutica

Praça Mal. Eduardo Gomes 50

12228-900 - São José dos Campos - SP

Karla Donato Fook - karla@ita.br

Instituto Tecnológico de Aeronáutica ITA

Praça Marechal Eduardo Gomes 50

12228-900 - São José dos Capos - SP

Cristiane Aparecida Martins - cmartins@ita.br

Instituto Tecnológico de Aeronáutica

Rua Dr Tito Roberto Liberato 63

12246150 - São José dos Campos - SP

Resumo: Desde a inserção da mulher no mercado de trabalho e seu acesso à educação, a sociedade passou por mudanças que ainda estão em andamento. As carreiras em áreas exatas, particularmente, em ciências, tecnologia, matemática, manufatura e design (STEM ${ }^{2} D$, Science, Technology, Engineering, Mathematics, Manufacturing, and Design) são, ainda, predominadas por homens. Devido à forte noção social de que existem carreiras "mais adequadas", a depender do gênero, a vida profissional de jovens no ensino básico é bastante influenciada pelo papel social e não somente por sua afinidade com determinada área. $O$ projeto

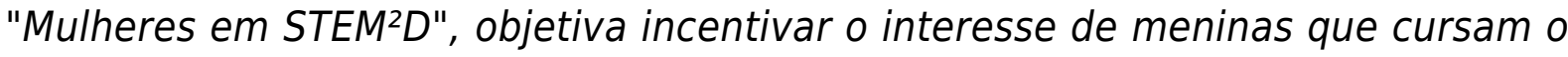
Ensino Básico em áreas de exatas. Este interesse é gerado por meio de atividades coordenadas por professoras, pesquisadoras e estudantes (graduação e pós-graduação) como uma forma de engajar o público-alvo mencionado. Dividido 
em frentes que contemplam a integração da comunidade interna e externa, o projeto está estruturado em subgrupos que atuam em categorias diversas, como gestão organizacional, marketing, rede, eventos, produção de textos, mentorias, cursos de programação, projetos de bioengenharia e oficinas experimentais. No entanto, com a pandemia de Covid-19 em 2020, restrições no convívio social comprometeram tais atividades. Assim, o projeto reinventou-se para continuar cumprindo seu objetivo, com a transição de aplicações de oficinas e cursos presenciais para o meio virtual. Neste trabalho, utilizou-se a frente de oficinais como prova de conceito e estudo de caso quanto à eficácia da transição do ensino presencial para o a distância, resultando na expansão da acessibilidade aos conteúdos desenvolvidos.

Palavras-chave: Projeto Mulheres em STEM²D. Oficinas. Ensino Básico. 


\section{PROJETO MULHERES EM STEM²D E A IMPLEMENTAÇÃO DE OFICINAS EXPERIMENTAIS: METODOLOGIAS ADAPTADAS DURANTE A PANDEMIA DA COVID-19}

\section{INTRODUÇÃO}

O projeto Mulheres em STEM ${ }^{2} \mathrm{D}$ foi criado em 2016 como uma parceria entre a empresa Johnson \& Johnson e o Instituto Tecnológico de Aeronáutica (ITA), com a finalidade de contribuir para o aumento do número de mulheres em cursos de graduação nas áreas de Ciências, Tecnologia, Engenharia, Matemática, Manufatura e Design (STEM ${ }^{2} \mathrm{D}$, na sigla em inglês). Trata-se de projeto de extensão, desenvolvido em conjunto com estudantes, professoras e pesquisadoras do ITA e financiado pela Johnson \& Johnson, tendo como foco atividades voltadas para alunas e também alunos do ensino fundamental e médio, de modo a incentivá-los a seguir e permanecer nas áreas de STEM²D.

O projeto possui três objetivos principais nas áreas de STEM ${ }^{2} D$, sendo estes: i. desenvolver atividades práticas que despertem a curiosidade e promovam o encantamento das garotas; ii. apoiar as alunas do ITA no desenvolvimento de habilidades técnicas e sociais a fim de engajá-las e reter talentos; iii. desenvolver canais de comunicação com a sociedade para discutir igualdade de gênero e ampliar a rede de mulheres.

Devido à pandemia do novo coronavírus (SARS-CoV2), mudanças significativas ocorreram no ano de 2020 e as atividades que eram realizadas de forma presencial nas escolas e em outras instituições tiveram de ser adaptadas ao formato on-line, sobretudo as atividades práticas, como as Oficinas, os Cursos de Programação e a Mentoria.

As Oficinas foram projetadas para despertar a curiosidade das meninas nas áreas de STEM $^{2} \mathrm{D}$, por meio de atividades hands-on, que promovem o conhecimento e a descoberta. Já os Cursos de Programação têm como objetivo divulgar as atividades de programação de computadores por meio de um curso de introdução à programação totalmente gratuito e virtual para um público de 14 anos ou mais. Por fim, o objetivo da Mentoria é tornar um grupo de meninas, entre 14 e 15 anos, mais apto a tomar as melhores decisões com relação a sua vida pessoal e profissional.

O projeto é estruturado em diversas frentes de atuação, como será visto na seção 2. Assim, o objetivo deste trabalho é dar destaque ao subgrupo das Oficinas, uma vez que é integrado por muitas participantes do projeto e realiza ações que afetam um maior número de instituições de ensino fundamental e médio. Assim, serão tratadas aqui as formas de adaptação das suas atividades, bem como as novas metodologias de alcance aos alunos e alunas e os possíveis resultados do novo formato.

Desse modo, as seções trabalho estão organizadas de forma a atender o objetivo citado no parágrafo acima, da seguinte forma: a seção 2 apresentará um panorama geral do projeto Mulheres em STEM²D; a seção 3 dedicar-se-á a apresentar a atuação das Oficinas, mediante o relato dos seus objetivos, metodologias, e adaptação para uma nova configuração, após o ano de 2020; e, na última seção, serão apresentadas as considerações finais do trabalho e perspectivas.

\section{VISÃO GERAL DO PROJETO MULHERES EM STEM²D}

Pode-se afirmar que o propósito geral do Projeto Mulheres em STEM²D consiste em desenvolver diversas ações voltadas a buscar uma maior inserção de meninas e mulheres nas áreas de Ciências, Tecnologia, Engenharia, Matemática, Manufatura e Design. Para 
tanto, o projeto está estruturado em distintas atuações, subdivididas em: gestão organizacional, marketing, rede, eventos, produção de textos, mentoria, oficinas, curso de programação e projetos de bioengenharia.

Cada frente é responsável pelo desenvolvimento de objetivos específicos e interdependentes. A Gestão Organizacional está voltada a operacionalizar um planejamento amplo e desenvolver atividades de integração entre os próprios membros do projeto de extensão. O Marketing promove o projeto nas comunidades interna e externa, com a prioridade de apoiar a sua identidade visual e aumentar a sua visibilidade para atingir um maior número de pessoas. As suas ações geram conteúdo para as redes sociais do projeto, sobretudo Instagram, e demandas provenientes de outras frentes, mais particularmente que envolvam a produção artística. A Rede cuida do engajamento do público-alvo nas redes sociais, produção de conteúdo digital, levantamento de assuntos relacionados aos interesses do projeto, formalização e integração da Rede Brasileira Mulheres em STEM, composta por instituições públicas e privadas de diferentes regiões do país e da organização das edições do Simpósio Brasileiro Mulheres em STEM ${ }^{2} D$. A frente de Eventos planeja, mais detidamente, os eventos realizados pelo projeto, de âmbito nacional e regional, inclusive das edições do Simpósio Brasileiro Mulheres em STEM²D, além de produzir lives, workshops e eventos on-line, abertos a todos os públicos, transmitidos no canal do projeto do YouTube. A Produção de Textos cuida, propriamente, do desenvolvimento de trabalhos científicos, a fim de que possam ser publicados em eventos acadêmicos, periódicos e outros meios de difusão internacionais e nacionais, contribuindo para que as ações do projeto sejam difundidas em diferentes searas do conhecimento.

Os subgrupos de Mentoria, Oficinas, Curso de Programação e Projetos de Bioengenharia são responsáveis pelo planejamento e execução de atividades desenvolvidas em conjunto com meninas e jovens do Ensino Básico. A frente Mentoria consiste em um trabalho contínuo de interação entre mentoras (equipe do projeto) e pupilas (estudantes do Ensino Médio), em que as primeiras procuram melhorar as habilidades de gestão, liderança e comunicação, transferir habilidades, conhecimentos e aperfeiçoar a visão das jovens sobre si mesmas e sobre o seu relacionamento com o mundo ao seu redor. À vista disso, o objetivo da mentoria em relação às estudantes em ensino escolar é estimular o desenvolvimento de habilidades de comunicação e autoconhecimento, aumentar o nível de confiança e autoestima e fornecer apoio e orientação, a fim de que elas possam escolher uma carreira. O Curso de Programação, por sua vez, oferta projetos de engenharia a jovens do Ensino Médio, com o escopo de apresentar um pouco do universo da engenharia à luz de abordagens divertidas e interessantes. Em cada edição são ensinados conceitos e desenvolvido algum protótipo relacionado a um curso de engenharia diferente. Os Projetos de Bioengenharia têm o propósito de mostrar a complexidade dos sistemas vivos, por meio de exemplos palpáveis, como o corpo humano, de forma a instigar a curiosidade sobre as ciências básicas nas crianças. Assim, esta frente procura demonstrar que a engenharia pode melhorar aspectos da saúde, como em procedimentos terapêuticos e equipamentos médicos, mediante aplicações práticas que tornem o processo de ensino e aprendizagem mais divertido e interativo.

Com a emergência da pandemia da Covid-19 (SARS-CoV2), as frentes do projeto que necessitavam de certa proximidade dos seus integrantes com o público-alvo foram impactadas no andamento dos seus trabalhos. Contudo, no intuito de dar continuidade às metas preestabelecidas no seu escopo, o projeto Mulheres em STEM ${ }^{2} D$ do ITA reinventouse para prosseguir com as atividades diretas realizadas com jovens cursando o Ensino Básico. 
Particularmente, as atividades desenvolvidas pela frente de Oficinas serão detalhadas neste trabalho, bem como seus impactos, eficácia e repercussões relacionadas à transição de um trabalho essencialmente presencial para o sistema a distância. O enfoque de pesquisa dado ao subgrupo das Oficinas justifica-se pela impossibilidade de se discorrer, dentro deste mesmo trabalho, sobre todas as adaptações realizadas no âmbito de cada uma das frentes do projeto em tela, bem como pelo fato de que as Oficinas tinham um maior número de integrantes e de pessoas afetadas, nos ensinos fundamental e médio, pelas ações efetuadas nos moldes presenciais.

\section{OFICINAS}

Esta seção discorrerá acerca das atividades das oficinas, seus objetivos, metodologias, e, principalmente, sobre como foi a adaptação para o formato virtual no ano de 2020. Assim, cabe, inicialmente, fazer uma breve descrição de como eram as atividades antes da pandemia.

Com a criação do projeto Mulheres em STEM²D no ano de 2016, as oficinas foram implementadas como uma das atividades práticas de maior alcance aos estudantes do ensino fundamental e médio. Estas eram oferecidas nas dependências do ITA até o ano de 2018, mediante inscrições feitas por meninas interessadas em participar. No ano de 2019, foi aprovado um projeto pelo CNPq (Conselho Nacional de Desenvolvimento Científico e Tecnológico), intitulado "Meninas nas Ciências Exatas, Engenharias e Computação", o qual possibilitou aos integrantes do projeto a integração com cinco escolas de São José dos Campos/SP. Assim, a partir daquele ano, várias oficinas foram ministradas por professoras e alunas do ITA para estudantes do ensino fundamental. Juntamente com as atividades citadas, as oficinas também eram oferecidas todos os anos na Semana de Engenharia do ITA e em parques localizados no município, como será descrito na subseção 3.2.

As oficinas possuem como objetivo principal o desenvolvimento de atividades práticas, por meio de workshops, com a finalidade de promoverem o encantamento, 0 conhecimento e a descoberta e, também, despertar a curiosidade de jovens nas áreas de $S_{\text {STEM }}^{2} \mathrm{D}$. Nesse âmbito, alunas e professoras do ITA apresentam os conceitos teóricos necessários, sempre com linguagem acessível, a estudantes de EB (Ensino Básico), e, na sequência, orientam os (as) jovens a realizarem algum experimento, em que os conceitos vistos são aplicados. Algumas atividades são feitas na forma de competição, a fim de estimular o raciocínio ágil e tornar tais atividades mais dinâmicas e interessantes. As oficinas geram uma quantidade de material replicável, com guia do instrutor e slides de apresentação das mesmas.

É importante mencionar que essas atividades oferecem oportunidades valiosas para os estudantes colocarem em prática o que acabaram de aprender. Além disso, tais práticas ajudam os alunos a ganhar confiança e compreensão de como o aprendizado se aplica à vida real (H.M. Madill et al., 2004; S. Kulturel-Konak et al., 2011).

Com vistas a atender os propósitos estipulados para o presente trabalho, serão expostas, nos próximos itens, as metodologias empregadas pela frente das oficinas do projeto Mulheres em STEM ${ }^{2}$ D antes da pandemia da Covid-19 e, depois, durante a mesma, a fim de que seja possível, mais à frente, levantar seus resultados e perspectivas.

\subsection{Metodologia empregada antes de 2020}

Nos anos de projeto anteriores à pandemia (2016 a 2019) foram desenvolvidas quatro estratégias distintas para ministrar as oficinas: "STEM em nosso instituto", "STEM em espaços públicos", "STEM em escolas", e "STEM com replicação nas escolas". De 
forma resumida, na esfera do "STEM em nosso instituto", alunas do Ensino Básico eram convidadas a irem ao ITA realizar atividades práticas. Já no campo do "STEM em espaços públicos", as alunas, integrantes do subgrupo das oficinas, ofereciam atividades práticas para o público que visitava espaços públicos, como parques, no município de São José dos Campos. Na seara do "STEM em escolas", a equipe do subgrupo ia a uma determinada escola e oferecia a atividade às crianças e jovens da mesma. Finalmente, a estratégia "STEM com replicação nas escolas" consistia em uma parceria com uma determinada equipe escolar, em que os integrantes do projeto ensinavam a equipe a realizar as atividades das oficinas e, posteriormente, a equipe poderia replicar tais atividades com os estudantes daquela instituição educacional. É relevante pontuar que, a maior parte das atividades ofertadas pelas oficinas, sejam em escolas ou nos parques, era realizada pelas alunas do projeto, a fim de que estas pudessem inspirar meninas e jovens, bem como oportunizar que os meninos, quando participantes, tivessem a percepção das habilidades e capacidades das mulheres nessas temáticas.

A Figura 1 mostra um exemplo da estratégia "STEM em espaços públicos", enquanto que a Figura 2 trata da vertente "STEM com replicação nas escolas", onde oficinas, que já foram executadas, são evidenciadas em ambas.

Figura 1 - Exemplo da estratégia "STEM em espaços públicos". Neste exemplo, a oficina "Fibra ótica com garrafa de plástico" foi ministrada por alunas do ITA.

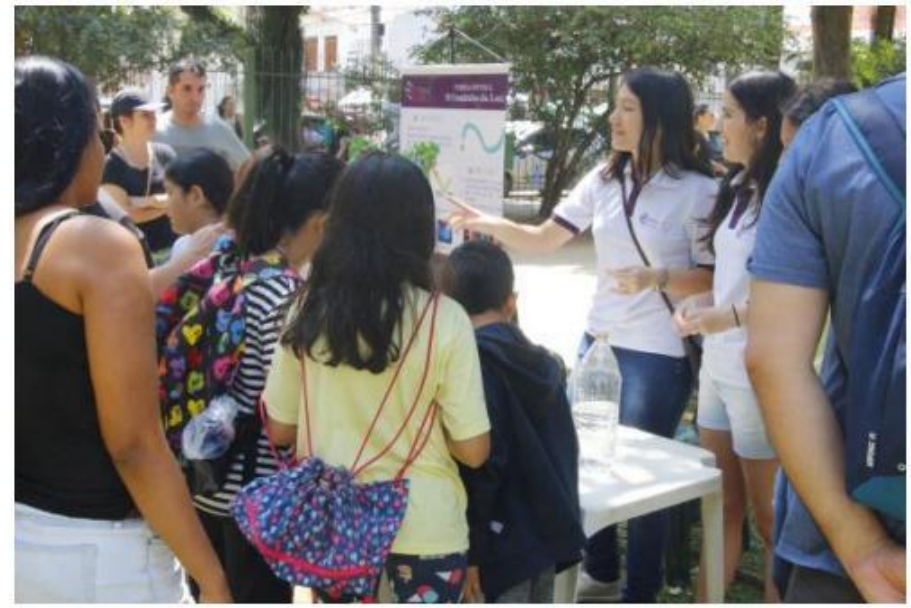

Fonte: Arquivo do projeto Mulheres em STEM²D.

As atividades possuíam duração de cerca de uma hora cada. Para cada atividade, dois documentos eram desenvolvidos: o manual do instrutor e a apresentação da oficina. O manual do instrutor define o público indicado para aquela atividade (por exemplo, idade das crianças ou jovens), o tempo estimado para a aplicação desta, o material necessário, a metodologia para explicar a teoria necessária e o procedimento para o experimento ou a prática. O material de apresentação foi o que o instrutor utilizou para aplicar a atividade de fato. Algumas atividades exigiam equipamentos ou materiais com um custo considerável, como as oficinas: "Construções Lego", "Introdução à Eletrônica e Programação, usando Arduino Uno" e "Impressora 3D". No entanto, a maioria das atividades concentrava-se em materiais de baixo custo, como: "Atividades com placas de plástico para aula de matemática", "Espectrômetro", "Fibra ótica com garrafa de plástico" (Figura 1), "Engenharia 
civil - Brincando com estruturas", e "Aprendizagem de geometria plana por meio de Geoboards" (Figura 2).

Figura 2 - Exemplo da estratégia "STEM com replicação nas escolas". Neste exemplo, a oficina "Aprendizagem de geometria plana por meio de Geoboards" foi replicada por uma professora da escola em questão.

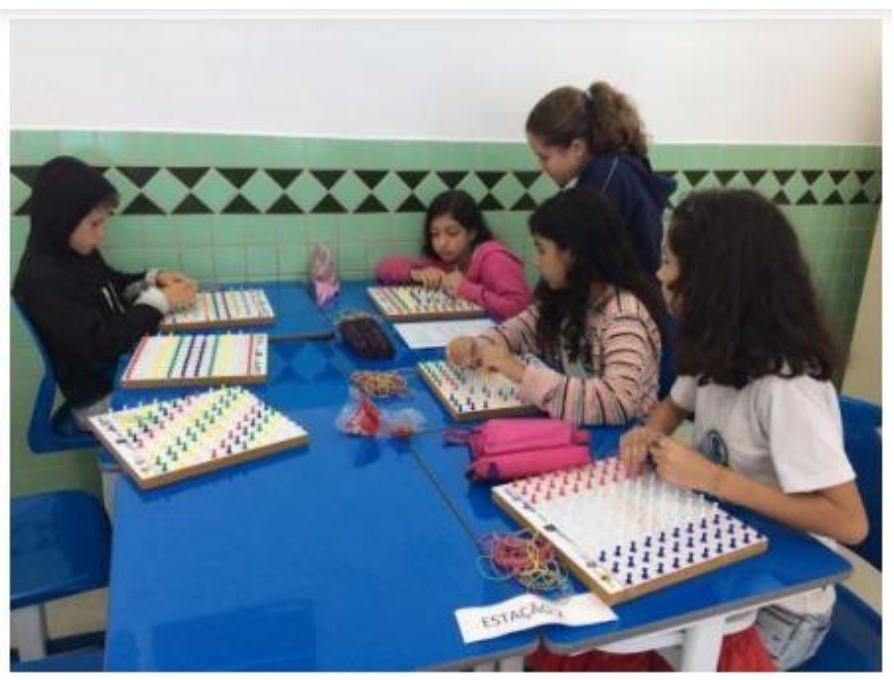

Fonte: Arquivo do projeto Mulheres em STEM²D.

\subsection{Metodologia empregada em 2020}

Os focos de atuação do subgrupo das oficinas estavam divididos da seguinte maneira: a) aplicação de oficinas em escolas, parques e outros eventos abertos ao público em geral; b) gravação de vídeos de oficinas e desenvolvimento de novas oficinas. A partir do ano de 2020, pela impossibilidade de realização de oficinas presenciais, uma nova organização foi implementada, utilizando bases de atuação direcionadas à produção de conteúdo digital.

Assim, o item "b" acima foi priorizado. Basicamente, vídeos passaram a ser produzidos a partir das atividades práticas já desenvolvidas pela equipe STEM ${ }^{2} \mathrm{D}$ e de novas oficinas elaboradas em 2020. Esses vídeos foram carregados no canal do YouTube do projeto, com o objetivo de atingir um público mais amplo, ajudando outros grupos que atuam no estímulo à participação feminina nas áreas de STEM²D, bem como professores (as) e alunos (as) a replicar atividades desenvolvidas pela equipe. Também é uma forma eficaz de divulgação de imagens que associem meninas e ciência, já que os vídeos foram produzidos pelas jovens do ITA. Eles estão divididos em duas categorias, quais sejam, "Você Sabia?" e "Oficina", as quais terão suas particularidades explicadas ainda nesta seção.

Conjuntamente, foram discutidas e elaboradas novas tipologias de oficinas, com o objetivo de alimentar o portfólio de projetos, gerando assim, novas opções de gravação de vídeos, conteúdo de e-books e, quando possível, aplicação em escolas e eventos. Para dar prosseguimento às atividades, o uso do canal do YouTube mostrou-se como uma opção para divulgação das oficinas em formato de vídeo, assim como eficaz na divulgação do 
projeto como um todo. Portanto, a aplicação deste novo recurso manifestou-se necessária para que as atividades do subgrupo das oficinas pudessem continuar.

A metodologia para a confecção dos vídeos se deu pela divisão da equipe, responsável pela execução das oficinas, em grupos, porém, cada integrante trabalhou remotamente para produzir dois tipos de vídeos a serem enviados ao canal do YouTube. $O$ primeiro tipo é um vídeo intitulado "Você sabia?", o qual é liberado a cada duas semanas, às quintas-feiras, com cerca de 2 minutos, abordando o objeto de estudo da oficina. $O$ segundo modelo de vídeo, intitulado "Oficina", é enviado a cada dois domingos, tendo uma duração um pouco maior, pois ele demonstra o passo a passo de uma determinada oficina. Nessa modalidade de vídeo, uma das integrantes do projeto realiza a atividade prática da oficina.

Com o intuito de evidenciar o alcance dos vídeos já publicados (nas suas duas modalidades), a Tabela 1 mostra a quantidade de vídeos e suas visualizações obtidas desde o envio destes para o canal, em 2020. A Tabela 1 permite constatar um significativo alcance que os vídeos das oficinas tiveram até o presente, o que implica afirmar que este formato tem se mostrado como uma alternativa às atividades presenciais.

Tabela 1 - Informações quantitativas sobre o alcance dos dois tipos de vídeos lançados pelo Grupo das Oficinas.

\begin{tabular}{c|c|c}
\hline Tipo & $\begin{array}{c}\text { Número de vídeos publicados até } \\
24 / 04 / 2021\end{array}$ & $\begin{array}{c}\text { Número de visualizações até } \\
24 / 04 / 2021\end{array}$ \\
\hline Você sabia? & 20 & 2070 \\
\hline Oficina & 19 & 2392 \\
\hline Total & 39 & 4462 \\
\hline
\end{tabular}

Fonte: Canal do YouTube "Mulheres em STEM2D" (link:

https://www.youtube.com/c/MulheresemSTEM2D/featured).

As oficinas presenciais contavam com kits individuais abrigando os materiais necessários à execução das mesmas. Assim sendo, em 2020, o grupo decidiu adquirir alguns kits individuais e entregá-los para os estudantes das escolas, a fim de que eles realizassem as oficinas em casa. Tais kits foram fornecidos a duas escolas parceiras do projeto (Escola Municipal Professora Maria Aparecida dos Santos Ronconi e Escola Estadual Prof Estevam Ferri), para que os estudantes pudessem buscá-los e levá-los para casa. Kits referentes a três oficinas foram entregues, sendo estas "Espectroscopia da luz", "Fluorescência e fosforescência" e "Cromatografia da Tinta". A Figura 3 mostra um exemplo de três kits enviados.

Figura 3 - Alguns exemplos de kits antes de serem enviados às escolas.

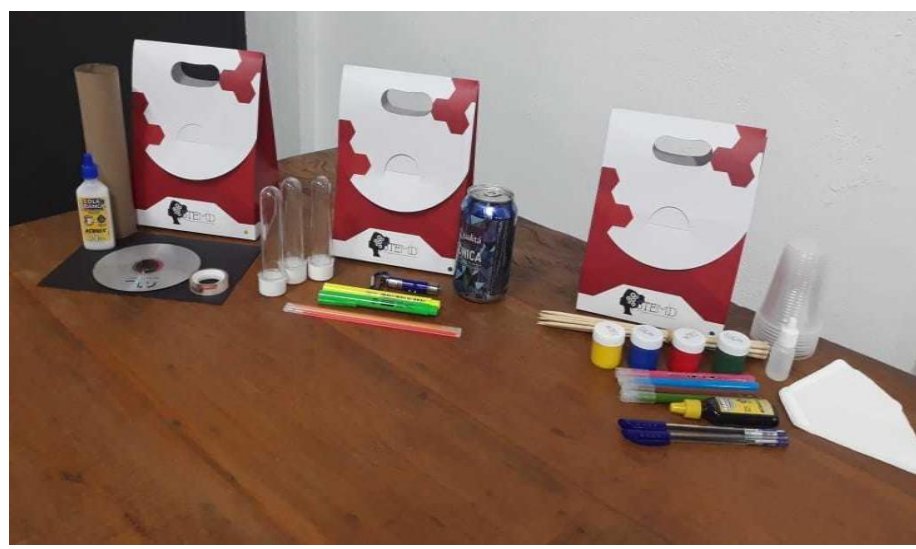


Fonte: Arquivo do projeto Mulheres em STEM²D.

Ao total, somaram-se 250 (duzentos e cinquenta) kits entregues aos alunos das duas escolas, sendo 180 (cento e oitenta) para a Escola Municipal Professora Maria Aparecida dos Santos Ronconi e 70 (setenta) à Escola Estadual Prof Estevam Ferri. Junto dos materiais necessários para a execução das oficinas (kits), também foi enviado um folheto impresso contendo instruções e curiosidades sobre o tema, além de um questionário sobre o experimento. As Figuras 4 e 5 são exemplos dos folhetos entregues em conjunto com os kits.

Figura 4 - Exemplo de folheto enviado à escola

Escola Municipal Professora Maria Aparecida dos

Santos Ronconi, como parte do kit referente à oficina

"Espectroscopia da luz".
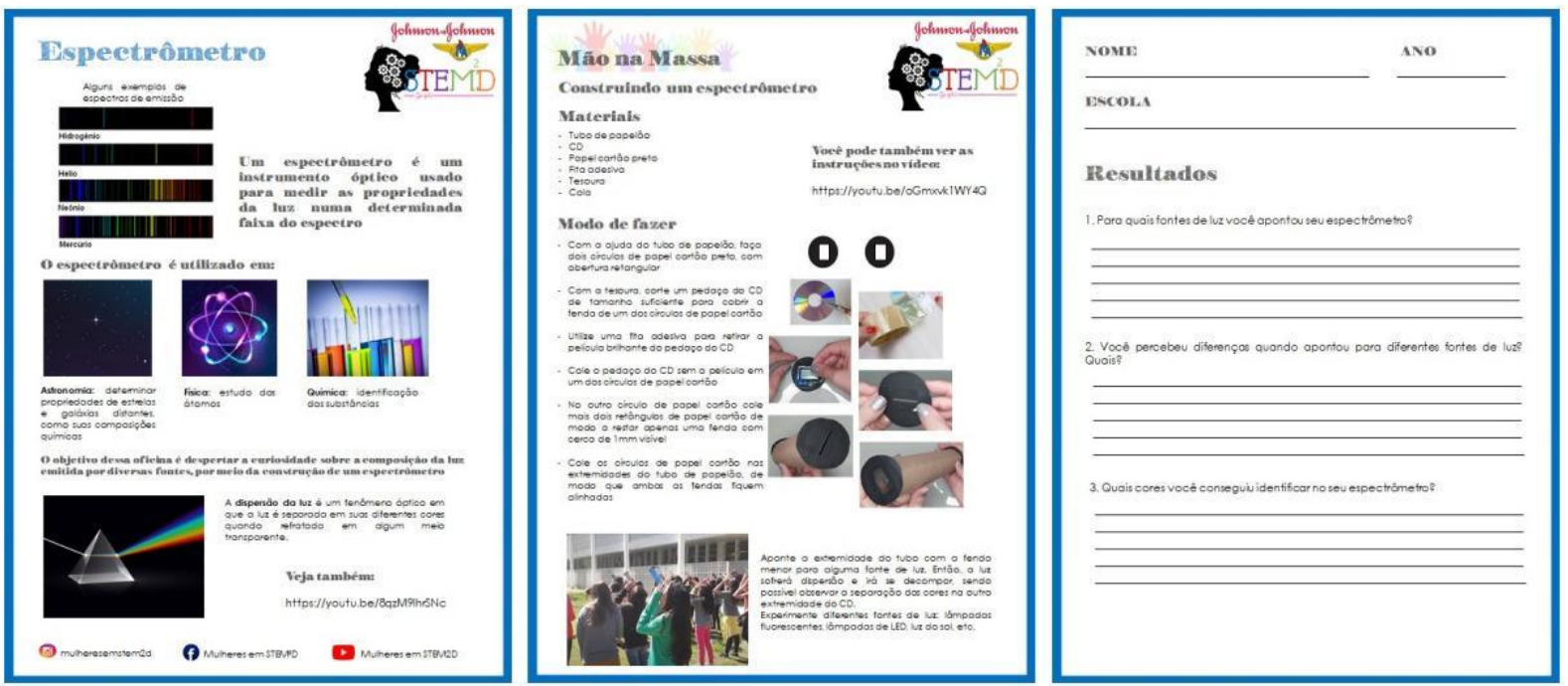

Fonte: Arquivo do projeto Mulheres em STEM²D.

Figura 5 - Exemplo de folheto enviado à escola

Escola Municipal Professora Maria Aparecida dos

Santos Ronconi, como parte do kit referente à oficina

"Fluorescência e fosforescência". 

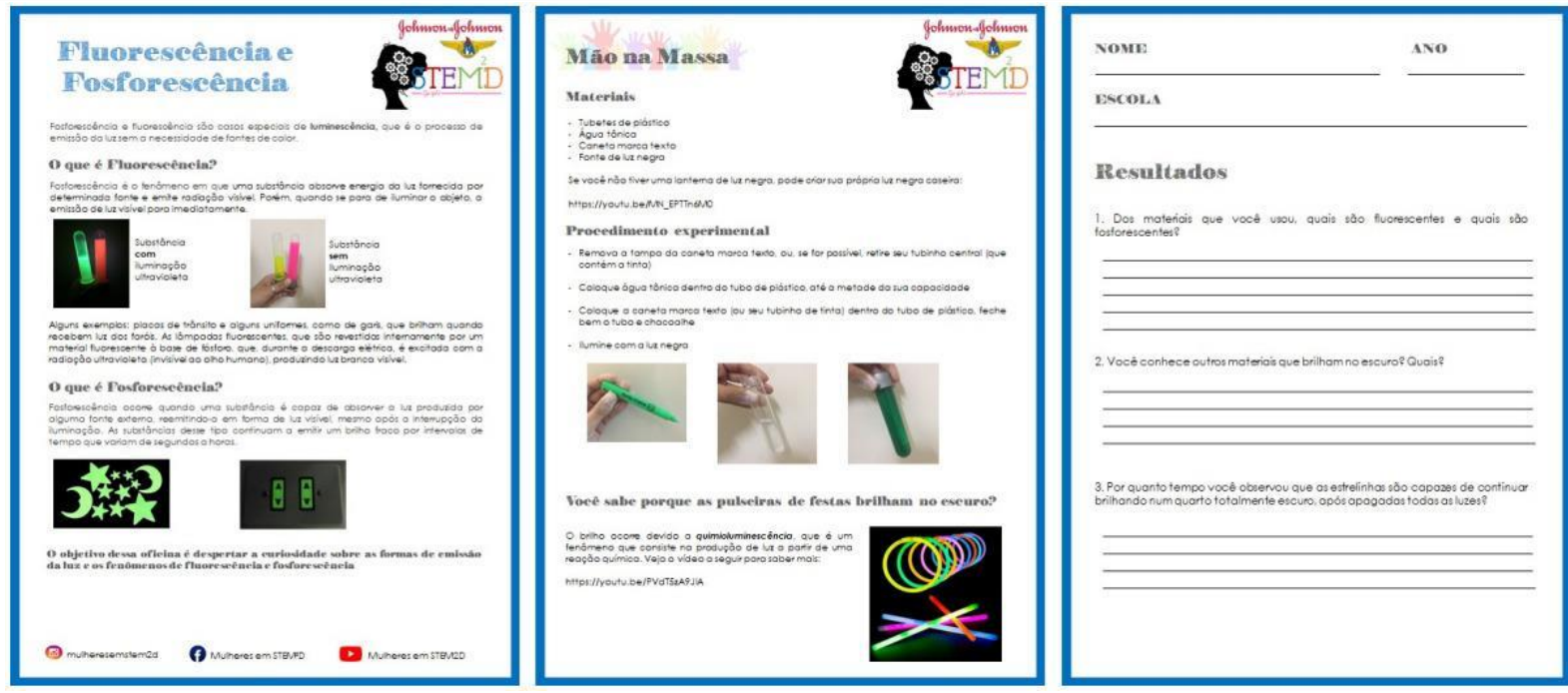

Fonte: Arquivo do projeto Mulheres em STEM²D.

\section{E-books}

É possível dizer que os novos desafios acarretados pela pandemia da Covid-19 no campo das oficinas do projeto Mulheres em STEM²D se, por um lado, implicou em uma transformação abrupta e significativa na metodologia das suas atividades, com vistas a suprir a necessidade imediata de continuidade de suas ações, por outro, possibilitou que novas abordagens pudessem ser engrenadas e até mesmo concretizadas em um cenário independente da crise sanitária presente. Em outras palavras, algumas ações, pensadas e criadas para existirem a partir do novo modelo virtual, acabaram tomando uma dimensão considerável, à medida que poderão permanecer como frentes de trabalho do projeto, ainda que se esteja em um contexto pós-pandêmico e de retorno ao trabalho presencial.

A ideia de se criar um E-book materializa esse movimento. Isso porque, durante a produção dos vídeos com a veiculação das oficinas, surgiu a ideia de se elaborar um material mais complexo (E-book), com o escopo de registrar e padronizar as oficinas existentes no projeto.

A produção de E-book visa consolidar as atividades do projeto Mulheres em STEM²D e, também, viabilizar sua publicação didático-científica por meio de divulgação eletrônica. Para tal, o E-book volta-se à transcrição das oficinas já aplicadas pelo projeto nas escolas e outros locais, incluindo a parte conceitual destas, ou seja, o embasamento teórico de uma determinada oficina. Uma primeira versão do layout de E-book das oficinas pode ser vista na Figura 6, na qual as capas são separadas pelas cores que representam cada uma das áreas de STEM ${ }^{2}$ D.

Figura 6 - Layout utilizado para o e-book das oficinas. 


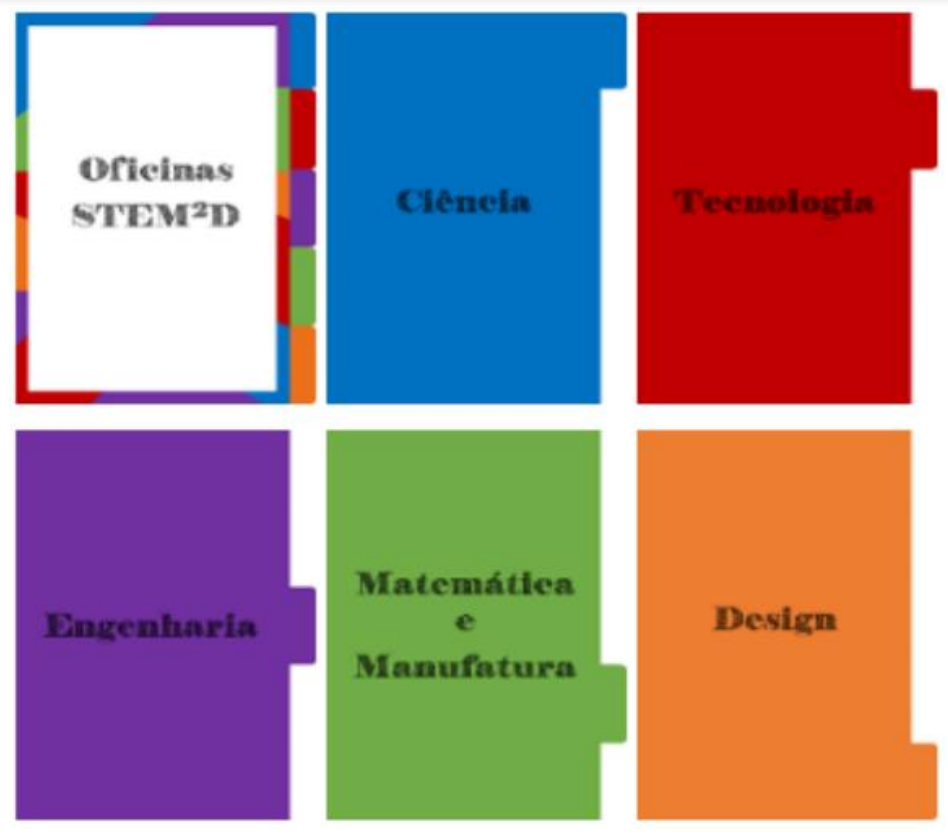

Fonte: Arquivo do projeto Mulheres em STEM²D.

O E-book "Oficinas do Projeto Mulheres em STEM²D" encontra-se em fase de produção, de modo que, para validar a divulgação do material, é proposto um fluxo de correções estéticas, conceituais e gramaticais entre membros do projeto, bem como convidados externos, especialistas nas áreas que envolvem cada atividade.

\section{CONSIDERAÇÕES FINAIS}

As carreiras em ciência, engenharia, tecnologia e áreas correlatas são, fundamentalmente, dominadas pelo gênero masculino (UNESCO, 2018, p. 11). Sem a ampliação do acesso à educação e a empregos para mulheres, muitas jovens não consideram possível seguir profissões, enraizadas na sociedade, como masculinas. Com isso, faz-se importante o incentivo dessas carreiras a jovens em formação, tal como promovido pelo Projeto de Extensão Mulheres em STEM $2 \mathrm{D}$, desenvolvido por professoras e estudantes do ITA em parceria com a empresa Johnson \& Johnson.

A partir de um panorama geral acerca das atuações específicas e interdependentes dos subgrupos organizados no âmbito do projeto Mulheres em STEM ${ }^{2} \mathrm{D}$, o presente trabalho teve o propósito de apresentar os principais desafios vivenciados pelo subgrupo oficinas, diante da pandemia da Covid-19. A eleição da frente oficinas como estudo de caso, deveu-se, sobretudo, ao fato de ser integrada por um grande número de membros do projeto e por realizar ações que afetam, em maior grau, instituições de ensino fundamental e médio envolvidas.

Como evidenciado, as oficinas do projeto Mulheres em STEM²D tem como objetivo desenvolver atividades práticas, por meio de workshops, de modo a fomentar o interesse, descoberta, conhecimento e curiosidade de jovens meninas para essas áreas. Assim, até o ano de 2020, a atuação das oficinas do projeto ocorria mediante o desenvolvimento de quatro estratégias metodológicas presenciais, quais sejam, "STEM em nosso instituto", consistente no recebimento de alunas do Ensino Básico no ITA, impulsionadas a desenvolverem atividades práticas; o "STEM em espaços públicos", voltado à oferta de experiências científicas e práticas para pessoas que visitavam espaços públicos do 
município de São José dos Campos; o "STEM em escolas", o qual exigia que integrantes do subgrupo fossem até as escolas públicas trabalhar com atividades relacionadas ao tema; e "STEM com replicação nas escolas", derivado de uma parceria com determinadas equipes escolares, a fim de implementar atividades de oficinas e possibilitar sua posterior replicação pelo corpo docente da instituição de ensino.

No entanto, com a chegada da pandemia ao Brasil, as oficinas presenciais precisaram sofrer significativa adaptação, de forma a possibilitar que suas ações permanecessem vigentes naquele momento. Estudantes das escolas públicas parceiras receberam kits referentes a oficinas, a fim de que pudessem realizá-las em casa, por meio de materiais instrutivos criados pelo subgrupo. Ao mesmo tempo, foram elaborados e carregados vídeos no canal do projeto do Youtube, em duas categorias distintas ("Você Sabia?" e "Oficina"), com o intuito de que o projeto pudesse atingir um público mais amplo.

Como pôde ser demonstrado, os dois formatos de vídeos desenvolvidos pelas novas metodologias das oficinas de 2020 têm atingido um número crescente de público (até abril de 2021, mais de quatro mil pessoas atingidas), situado, inclusive, em localidades distintas de onde o projeto de extensão estava sendo desenvolvido inicialmente (São José dos Campos/SP). Além disso, novas reflexões sobre as atividades das oficinas puderam ser projetadas para um cenário de médio e longo prazos (pós-pandêmico), como é o caso da elaboração de publicações seriadas do E-book Projeto Mulheres em STEM²D.

Em linhas gerais, pode-se afirmar que uma parte considerável das atividades projetadas para 2020, antes da ocorrência da pandemia, foi possível de ser realizada, mesmo em meio ao processo abrupto de adaptação dos trabalhos e reformulações específicas. Ademais, as novas atividades criadas, dentro do cenário de crise sanitária, têm a perspectiva de se tornarem permanentes e simultâneas às ações presenciais, quando do retorno das atividades regulares.

\section{Agradecimentos}

Um agradecimento especial à Johnson \& Johnson, a qual financiou este projeto.

\section{REFERÊNCIAS}

H.M. Madill et al. The potential to develop a career in science: Young women's issues and their implications for careers guidance initiatives. International Journal for the Advancement of Counseling, vol. 26, n. 1, pp. 1-19, 2004.

S. Kulturel-Konak et al. Review Of Gender Differences In Learning Styles: Suggestions For STEM Education. Contemporary Issues In Education Research, vol. 4, n. 3, 2011.

Organização das Nações Unidas para a educação, a ciência e a cultura (UNESCO). Decifrar o código: educação de meninas e mulheres em ciências, tecnologia, engenharia e matemática (STEM). Brasília: UNESCO Brasil, 2018. Disponível em: https://ead2.iff.edu.br/pluginfile.php/138994/mod resource/content/1/Decifrar\%200\%20CO DIGO.pdf. Acesso em: 06 mai. 2021. 


\title{
WOMEN IN STEM²D PROJECT AND THE IMPLEMENTATION OF EXPERIMENTAL WORKSHOPS: ADAPTED METHODOLOGIES DURING THE COVID-19 PANDEMIC
}

\begin{abstract}
Since the entry of women into the job market and their access to education, society has undergone changes that are still underway. Careers in exact sciences, particularly in science, technology, engineering, mathematics, manufacturing, and design $\left(S T E M^{2} D\right)$ are almost entirely occupied by men. Due to the strong social notion that there are "more suitable" careers, depending on gender, the professional life of students in basic education is greatly influenced by the social role instead of affinity with the area. The "Women in STEM D" project aims to increase the interest of girls in Basic Education to the exact sciences. This interest is generated by activities coordinated by college professors, researchers and students as means of engaging the aforementioned target group. Divided into fronts that contemplate the integration of the internal and external community, the project is structured in subgroups that operate in different categories, such as organizational management, marketing, network, events, text production, mentoring, programming courses, bioengineering projects, and experimental workshops. However, with the Covid-19 pandemic in 2020, restrictions on social interaction compromised such activities. Thus, the project reinvented itself to continue fulfilling its objective, transitioning from doing workshops and face-to-face courses to the virtual environment (e-learning). In this work, the group of workshops was used as a proof-of-principle and a case study regarding the effectiveness of the transition from face-to-face to the e-learning environment, resulting in expanding access to the contents developed.
\end{abstract}

Keywords: Women in STEM²D Project. Workshops. Basic education. 